\title{
The relation of pulsatility indices of middle cerebral, umbilical and uterine arteries with birth weight in normal pregnancies
}

\section{Normal gebelerde doğum ağırlığı ile orta serebral, umbilikal ve uterin arter pulsatilite indekslerinin ilişkisi}

Eda Albayrak, Orhan Solak, Sultan Şalk, İsmail Şalk*, Mübeccel Arslan, Ali Çetin, Mustafa İşleyen

Clinic of Radiology (E. Albayrak, MD), Sivas State Hospital, TR-58000 Sivas, Department of Radiology (Prof. O. Solak, MD, Assist. Prof. İ. Şalk, MD, Prof. M. Arslan, MD), Cumhuriyet University School of Medicine, TR-58140 Sivas, Clinic of Obsterics and Gynecology (S. Şalk, MD), Sivas State Hospital, TR-58000 Sivas, Department of Obsterics and Gynecology (Prof. A. Çetin, MD), Near East University Hospital, Lefkosa, Mersin 10 Turkey, Clinic of Radiology (M. İşleyen, MD), Elbistan State Hospital, TR-46300 Elbistan/Kahramanmaraş

\begin{abstract}
Aim. The aim of this study was to assess the relation between middle cerebral to umbilical artery pulsatility index ratio and uterine artery pulsatility and resistive indices with birth weights in normal pregnancies. Methods. The pulsatility indices were obtained together with the birth weight from 160 healthy pregnancies. Measurements were done at five weeks intervals from 20 weeks' gestation until delivery. A relationship between indices and birth weight was sought at gestational age ranges of 20 th to 40th weeks. Results. The values of pulsatility indices towards to 40th weeks of gestation were decreased progressively. There was a correlation between the pulsatility indices of uterine and the middle cerebral arteries nd the birth weights of cases. Conclusion. Doppler pulsatility index measurements can be valuable in detecting birth weight.
\end{abstract}

Keywords: Pulsatility index, middle cerebral artery, umbilical artery, uterine artery, birth weight

\section{Özet}

Amaç. Bu çalışmanın amacı normal gebelerde orta serebral arter- umbilikal arter pulsatilite indeksi oranı ve uterin arter pulsatilite ve rezistif indekslerinin doğum ağırlıkları ile ilişkisini değerlendirmektir. Yöntem. Yüzaltmış sağlıklı gebeden pulsatilite indeksleri ile birlikte doğum ağırlıkları elde edildi. Ölçümler 20. haftadan itibaren doğuma kadar beșer hafta aralıklarla yapıldı. 20-40. gebelik haftalarındaki indeksler ve doğum ağırlığı arasındaki ilişki araştırıldı. Bulgular. Gebeliğin 40. haftasına doğru pulsatilite indekslerinin değerleri giderek azaldı. Uterus ve orta serebral arterlerin pulsatilite indeksleri ve olguların doğum ağırlıkları arasında bir korelasyon vardı. Sonuç. Doppler pulsatilite indeksleri ölçümü doğum ağırlığını saptamada değerli olabilir. Anahtar sözcükler: Pulsatilite indeksi, orta serebral arter, umblikal arter, uterin arter, doğum ağırlığ 1

Geliş tarihi/Received: December 14, 2011; Kabul tarihi/Accepted: July 30, 2012

\section{*Corresponding author:}

Dr. İsmail Şalk, Radyoloji Anabilim Dalı, Cumhuriyet Üniversitesi Tıp Fakültesi, TR-58140 Sivas.E-mail: ismailsalk@gmail.com

\section{Introduction}

The determination of intrauterine growth restriction (IUGR) relies on risk evaluation and observation. IUGR is diagnosed by ultrasound biometry. The next question is how to identify which fetus is at risk? [1]. The screening for preeclampsia is provided by uterine artery Doppler velocimetry at 22 week of gestation [2, 3]. In IUGR, the pulsatility index (PI) of the umbilical artery is increased, while the middle cerebral artery's (MCA) is decreased. A precursor study reported that peak systolic velocity of MCA is increased in IUGR fetuses, suggesting that it would be a foretelling of perinatal mortality [4]. The 
fetal response of hypoxia is increased blood flow to the brain, as called the "brain sparing effect". If the placental disease progresses, the fetus cannot keep his vital organs functioning and finally leading to disorder of acid-base disturbance and death [5]. Doppler ultrasound in the second trimester is suggested as potential screening test for preeclampsia and intrauterine growth restriction. An abnormal uterine artery Doppler waveform indicates increased resistance in the uterine circulation. The uterine artery Doppler as a screening method for poor pregnancy outcome is restricted by variable methods and various gestational ages. The uterine artery waveform indices to obtain the positive predictive value for preeclampsia or IUGR are not clear yet $[6,7]$. A lack of the vascular trophoblastic invasion has been related with pregnancy disorders [8]. Previous studies have demonstrated an increase in the uterine artery resistance due to lack of this invasion. Increased flow resistance in the capillaries of the placenta causes a low enddiastolic velocity in the umbilical artery and subsequent hypoxia. Due to the prolonged fetal hypoxia, circulatory adaptation begins, so cerebral vasodilatation provides sufficient oxygen supply to the brain [9]. Uterine artery Doppler indices are noninvasive methods for evaluation of uteroplacental circulation. The indices as a screening method for cases with preeclampsia or IUGR indicate increased risk of poor outcomes [10]. Doppler velocimetry of uterine arteries at second and third trimester of pregnancy should be useful to determine the risk in patients with preeclampsia or IUGR [11]. The evaluation of umbilical artery Doppler indices in high risk pregnancy has been associated with reduction in perinatal deaths [12]. Prenatal umbilical artery Doppler evaluation is an effective marker in predicting poor perinatal outcome in IUGR fetuses [13].

The purpose of this study was to assess the accuracy of the middle cerebral to umbilical artery pulsatility index ratio and uterine artery pulsatility and resistive indices in postpartum evaluation of birth weights in normal pregnancies. The value of these parameters was evaluated for the prediction of brain lesions caused by fetal hypoxia, preeclampsia, intrauterine growth restriction, and low birth weight.

\section{Materials and methods}

\section{Study population and Doppler assessment}

This prospective study was carried out in the, Radiology Clinic, of between Cumhuriyet University January 2009 and December 2009. Research sample included 160 healthy pregnants. The study was approved by the Human Ethics Committee of Sivas Province, and all participants gave written informed consent. Measurement of fetal cerebral circulation changes was performed on the ultrasound apparatus Logic 9 (GE Healthcare, Milwaukee, WI, USA) with Doppler features. We used convex probe with frequency of 3.5 MHz. maximum emission energy of the device was below the limits approved for use in fetal medicine, in both imaging and Doppler modes. Doppler ultrasound was performed while the women lying in a semi-recumbent position, taking care of the absence of fetal movements and a fetal heart rate between 120 and $160 \mathrm{bpm}$. The transducer was placed on the left and right lower quadrant of the maternal abdominal wall, visualizing the uterine artery. Flow velocity waveforms were obtained from each uterine artery near to the external iliac artery. Umbilical artery pulsatility index was estimated on a free loop of cord. For measurements of the middle cerebral artery pulsatility index, an axial view of the fetal head was obtained at the level of the cerebral peduncles. Color Doppler was used to visualize the circle of Willis. The Doppler sample volume was placed within $1 \mathrm{~cm}$ lateral of the origin of the middle cerebral arteries. The maximum and minimum values of the velocity waveforms on the frozen image were measured by use of electronic calculations of the ultrasound machine. Fetal weight was determined on the basis of fetal biparietal diameter, abdominal circumference, and femur length. Fetal weight was estimated according to Haddlock et al. [14]. We evaluated pregnants five times at the $20^{\text {th }}, 25^{\text {th }}, 30^{\text {th }}, 35^{\text {th }}$, and $40^{\text {th }}$ weeks of gestation. 


\section{Statistical analysis}

The SPSS 14.0 software package (SPSS Inc., Chicago, IL, USA) was used for statistical analyses. Age, pulsatility and resistive indices of uterine, pulsatility index of middle cerebral and umbilical arteries were recorded. Age and uterine, middle cerebral and umbilical arteries indices of the pregnants were analyzed with ANOVA test. Correlation of MCA/Umblical artery pulsatility ratio and birth weight was analyzed with Pearson correlation test. Significance was determined at the $\mathrm{p}<0.05$ level.

\section{Results}

One hundred sixty healty pregnants were enrolled and followed-up until the end of pregnancy. Mean maternal age was 26.6 \pm 5.6 (range 18-39) years. The mean values of uterine artery pulsatility and resistive indices, middle cerebral and umbilical arteries pulsatility indices are given in Table 1 . The values at 20-40th weeks of gestation were decreased progressively.

Table 1. The mean Doppler indices of 160 pregnants are shown according to gestational weeks.

\begin{tabular}{llllll}
\hline & $\mathbf{2 0}^{\text {th }}$ week & $\mathbf{2 5}^{\text {th }}$ week & $\mathbf{3 0}^{\text {th }}$ week & $\mathbf{3 5}^{\text {th }}$ week & $\mathbf{4 0}^{\text {th }}$ week \\
\hline UA PI & $1.15 \pm 0.34$ & $0.95 \pm 0.33$ & $0.83 \pm 0.30$ & $0.75 \pm 0.28$ & $0.72 \pm 0.27$ \\
UA RI & $0.57 \pm 0.11$ & $0.52 \pm 0.11$ & $0.48 \pm 0.11$ & $0.46 \pm 0.10$ & $0.45 \pm 0.10$ \\
MCA PI & $1.83 \pm 0.28$ & $1.90 \pm 0.26$ & $1.82 \pm 0.26$ & $1.58 \pm 0.23$ & $1.29 \pm 0.20$ \\
Um A PI & $1.65 \pm 0.30$ & $1.36 \pm 0.30$ & $1.07 \pm 0.26$ & $0.93 \pm 0.25$ & $0.81 \pm 0.23$ \\
\hline
\end{tabular}

UA: Uterine artery; MCA: Middle cerebral artery; Um A: Umbilical artery; PI: Pulsatility index; RI: Resistive index. Data are expressed as mean \pm SD.

We recorded mean birth weights of pregnants $3555.7 \pm 428.4$ (range 2800-4400). There was significant positive correlation between mean uterine PI's of 25th, 30th, 35th, and 40th gestational weeks and the middle cerebral arteries PI's of 35th and 40th gestational weeks and the birth weights of cases $(\mathrm{p}<0.05)$. In addition there was no significant correlation between the umbilical artery PI and the birth weights of cases ( $>>0.05)$. Figure 1 shows the correlation between mean of MCA/Um A PI ratio and the birth weights of cases. There was no significant correlation between the mean of MCA/Um A PI ratio and the birth weights of cases ( $>0.05)$.

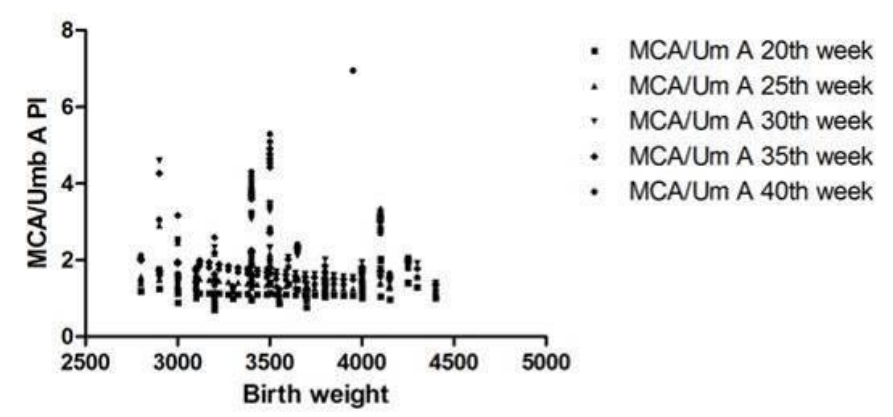

Figure 1. The correlation between means of MCA/Um A ratio and the birth weights of cases.

\section{Discussion}

In this cross-sectional and longitudinal assessment of the uterine, middle cerebral and umbilical arteries pulsatility indices in healthy pregnancies, our data have shown that, the values at 20-40th weeks of gestation were decreased progressively. However, there were correlation between mean uterine and the middle cerebral arteries PI and the birth weights of cases and there was no significant correlation between the means of MCA/Um A ratio and the birth weights of cases. 
Doppler ultrasound monitoring has become an important component in the antepartum surveillance of pregnancies. Birth weight depends on many variables including maternal weight, ethnicity, parity, and the gestational age. The clinical value of middle cerebral, umbilical and uterine artery Doppler has been investigated by many researchers. Very few previous publications regarding middle cerebral, umbilical, and uterine artery Doppler and fetal growth restriction have used the regional birth-weight approach. We aimed to provide the prevalence of normal findings using our data and establish cutoffs in Turkish people.[Figueras et al. [15] investigated relationship between low birth weight and umbilical artery Doppler in the prediction of adverse outcome]. In that study, a total of 7645 singleton pregnancies were evaluated. They concluded that normal antenatal umbilical artery Doppler cannot be taken as an indicator of low risk in pregnancies where the fetus is SGA according to customized percentiles. Axt-Fliedner et al. [7] determined value of uterine artery Doppler in a risk population for the prediction of severe pregnancy complications. In that study 56 pregnant women were evaluated and performed on women with singleton "risk" pregnancies in between 19 and 26 completed weeks' gestation. They suggested that Doppler ultrasound of the uterine artery in the second trimester of gestation is a useful method to predict abnormal outcomes in risk pregnancies. Tchirikov et al. [16] assessed the diagnostic power of umbilical venousarterial index (VAI), umbilical artery pulsatility index, and blood flow volume in umbilical vein for prediction of poor fetal outcome. Umbilical artery (UA), uterine artery (utA), the middle cerebral artery (MCA), and aorta were determined in 181 fetuses once (at between 17-41weeks of gestation) during pregnancy using Doppler ultrasound. They concluded that combination of umbilical artery PI and the venous-arterial index can be used to predict fetal outcome. Sankaran et al. [8] examined the relationship between uterine artery Doppler measurement at 19 to 23 weeks and birth weight. They evaluated 2035 pregnancies scanned at 19 to 23 weeks. They suggested lower sensitivity of uterine artery Doppler screening for fetal growth restriction as compared with preeclampsia. Owen et al. [17] investigated the relation between the umbilical artery impedance (PI and $\mathrm{S} / \mathrm{D}$ ) and sonographically determined EFW in the third trimester. In that study the pulsatility index (PI) and S/D (systolic/diastolic) ratio were obtained from 274 low-risk pregnancies. They suggested that it was not necessary to adjust umbilical artery Doppler impedance indices to account for fetal size. Mari et al. [18] evaluated the middle cerebral artery peak systolic velocity in IUGR fetuses compare the performance of MCA pulsatility index (PI), MCA-PSV and umbilical artery (UA) absent/reversed end-diastolic velocity in predicting perinatal mortality, and to determined the changes that occur in MCA-PI and MCA-PSV. It was a retrospective cross-sectional study of 30 IUGR fetuses in which the last MCA-PI, MCA-PSV and UA values were obtained. In their study high MCA-PSV predicted perinatal mortality better than low MCA-PI.

Konje et al. [19] investigated the changes of uterine artery flow volume in pregnancies with intrauterine growth restriction and then compared them with appropriate for gestational age (AGA) pregnancies. They prospectively measured uterine artery Doppler velocimetry at 20 and 24 weeks of gestation in 32 pregnant women with risk factors for IUGR and in 25 women with no risk factos for IUGR at the 20 and 38 weeks of gestation. They suggested that proximal uterine artery diameter and volume changes with gestation and showed significant differences between AGA pregnancies and IUGR. These changes occurred early and become more marked as pregnancy advances.

Ebrashy et al. [9] investigated that the middle cerebral to umbilical artery resistance index ratio in pregnancies complicated by preeclampsia with or without IUGR and found sensitivity in high-risk pregnancies. They evaluated 50 pregnant women with preeclampsia with or without intrauterine growth restriction. They proved middle cerebral to umbilical artery resistance index ratio $<1$ may be helpful in identification of newborns at risk of morbidity. Da Silva et al. [20] determined significant predictors for adverse neonatal outcome in severe fetal compromise. They examined prospectively 46 consecutive premature fetuses at between 25 and 32 weeks with severe placental 
insufficiency. They concluded that pathological Doppler findings with fetal weight $\mathrm{Z}$ score index can identify the fetus at risk for neonatal mortality and morbidity.

Evaluation of uterine, umbilical and middle cerebral arteries Doppler ultrasound can be a useful procedure in clinical practice for pregnants. To determine if the use of regional data will confer an overall clinical benefit will require large-scale prospective studies, as perinatal mortality is an infrequent event even in this high-risk group.

\section{References}

1. Coomarasamy A, Fisk NM, Gee H, Robson SC. The Investigation and Management of the Small-for-Gestational-Age Fetus. Green-Top Guidelines. London, UK: Royal College of Obstetrics and Gynaecology 2002.

2. Yu CK, Smith GC, Papageorghiou AT, Cacho AM, Nicolaides KH; Fetal Medicine Foundation Second Trimester Screening Group. An integrated model for the prediction of preeclampsia using maternal factors and uterine artery Doppler velocimetry in unselected low-risk women. Am J Obstet Gynecol 2005; 193: 429-36.

3. Campbell S, Diaz-Recasens J, Griffin DR, Cohen-Overbeek TE, Pearce JM, Willson K, Teague MJ. New doppler technique for assessing uteroplacental blood flow. Lancet 1983; 1: 675-7.

4. Ozcan T, Sbracia M, d'Ancona RL, Copel JA, Mari G. Arterial and venous Doppler velocimetry in the severely growth-restricted fetus and associations with adverse perinatal outcome. Ultrasound Obstet Gynecol 1998; 12: 39-44.

5. Bahado-Singh RO, Kovanci E, Jeffres A, Oz U, Deren O, Copel J, Mari G. The Doppler cerebroplacental ratio and perinatal outcome in intrauterine growth restriction. Am J Obstet Gynecol 1999; 180: 750-6.

6. Chien PF, Arnott N, Gordon A, Owen P, Khan KS. How useful is uterine artery Doppler flow velocimetry in the prediction of pre-eclampsia, intrauterine growth retardation and perinatal death? An overview. BJOG 2000; 107: 196-208.

7. Axt-Fliedner R, Schwarze A, Nelles I, Altgassen C, Friedrich M, Schmidt W, Diedrich K. The value of uterine artery Doppler ultrasound in the prediction of severe complications in a risk population. Arch Gynecol Obstet 2005; 271: 53-8. Epub 2004 Jun 3.

8. Sankaran S, Prefumo F, Papageorghiou A, Thilaganathan B, Bhide A. Association of uterine artery Doppler resistance index and birth weight: effect of customized birth weight standards. Am J Perinatol 2009; 26: 501-5. Epub 2009 Mar 13.

9. Ebrashy A, Azmy O, Ibrahim M, Waly M, Edris A. Middle cerebral/umbilical artery resistance index ratio as sensitive parameter for fetal well-being and neonatal outcome in patients with preeclampsia: case-control study. Croat Med J 2005; 46: 821-5.

10. Vink J, Hickey K, Ghidini A, Deering S, Mora A, Poggi S. Earlier gestational age at ultrasound evaluation predicts adverse neonatal outcomes in the preterm appropriate-for-gestational-age fetus with idiopathic oligohydramnios. Am J Perinatol 2009; 26: 21-5. Epub 2008 Oct 8.

11. Rampello S, Frigerio L, Ricci E, Rota E, Lucianetti M, Parazzini F. Transabdominal uterine arteries Doppler at 12-14th and 20-24th week of gestation and pregnancy outcome: a prospective study. Eur J Obstet Gynecol Reprod Biol 2009; 147: 135-8. Epub 2009 Aug 26.

12. Neilson JP, Alfirevic Z. Doppler ultrasound for fetal assessment in high risk pregnancies. Cochrane Database Syst Rev 2000; (2):CD000073.

13. Byun YJ, Kim HS, Yang JI, Kim JH, Kim HY, Chang SJ. Umbilical artery Doppler study as a predictive marker of perinatal outcome in preterm small for gestational age infants. Yonsei Med J 2009; 50: 39-44. Epub 2009 Feb 24.

14. Hadlock FP, Harrist RB, Sharman RS, Deter RL, Park SK. Estimation of fetal 
weight with the use of head, body, and femur measurements--a prospective study. Am J Obstet Gynecol 1985; 151: 333-7.

15. Figueras F, Eixarch E, Gratacos E, Gardosi J. Predictiveness of antenatal umbilical artery Doppler for adverse pregnancy outcome in small-for-gestationalage babies according to customised birthweight centiles: population-based study. BJOG 2008; 115: 590-4.

16. Tchirikov M, Strohner M, Förster D, Hüneke B. A combination of umbilical artery PI and normalized blood flow volume in the umbilical vein: venous-arterial index for the prediction of fetal outcome. Eur J Obstet Gynecol Reprod Biol 2009; 142: 129-33. Epub 2009 Jan 10.

17. Owen P, Murphy J, Farrell T. Is there a relationship between estimated fetal weight and umbilical artery Doppler impedance indices? Ultrasound Obstet Gynecol 2003; 22: 157-9.

18. Mari G, Hanif F, Kruger M, Cosmi E, Santolaya-Forgas J, Treadwell MC. Middle cerebral artery peak systolic velocity: a new Doppler parameter in the assessment of growth-restricted fetuses. Ultrasound Obstet Gynecol 2007; 29: 310-6.

19. Konje JC, Howarth ES, Kaufmann P, Taylor DJ. Longitudinal quantification of uterine artery blood volume flow changes during gestation in pregnancies complicated by intrauterine growth restriction. BJOG 2003; 110: 301-5.

20. da Silva FC, de Sá RA, de Carvalho PR, Lopes LM. Doppler and birth weight Z score: predictors for adverse neonatal outcome in severe fetal compromise. Cardiovasc Ultrasound 2007; 5: 15. 